\title{
Predicting Students' Intentions to Create Green Start-ups: A Theory of Planned Behaviour Approach
}

\author{
Ahmed Chemseddine Bouarar ${ }^{1, *}$, Smail Mouloudj ${ }^{2}$, Asma Makhlouf ${ }^{1}$, Kamel Mouloudj ${ }^{1}$ \\ ${ }^{1}$ University of Medea, Department of Commercial Sciences, 26000, Algeria, Spain \\ ${ }^{2}$ University of Medea, Department of Commercial Sciences, 26000, Algeria \& Visiting Researcher at University of Salamanca, Spain
}

\begin{abstract}
Start-ups play a fundamental role in the economy and have contributed enormously and effectively to solving economic and social issues. However, despite the significant environmental hazards the world is experiencing, the environmental dimension of its contribution is still significantly low, and the transition to green start-ups is still in its infancy especially in developing countries. The aim of the paper is to identify the factors that influence students' intentions to create green start-ups. Based on a convenience sample of 248 university students, a multiple regression analysis was performed to test our extended model. The empirical findings show that attitudes, subjective norms, perceived behavioural control (PBC), and environmental awareness positively influence the intention to create green start-ups. In addition, the findings demonstrate that students have a low level of environmental awareness. Based on the results, suggestions are provided on how to motivate university graduates to create green start-ups.
\end{abstract}

Keywords: eco-friendly behaviour; environmental awareness; green entrepreneurship; sustainability

\section{Introduction}

As environmental changes are occurring faster than expected, the world perceives a growing need to adopt more environmentally sustainable approaches [1], one of them being the green economy. In the green economy, both public and private sectors' investments related to reducing carbon emission and pollution, increasing energy and resources efficiency, and preserving biodiversity and ecosystem services are the drivers for increasing income and employment [2]. The green economy also helps in overcoming environmental problems, depletion of natural resources, and ensuring the well-being of people at the lower position of the economic pyramid. Green entrepreneurship is considered as key component of the green economy. In the context of the sustainable development, the idea of green entrepreneurship is gaining a significant attention.

Shepherd and Patzelt [3] argue that green entrepreneurship helps preserve the ecosystem, improve the environmental quality and mitigate deforestation. Green entrepreneurship is playing an increasingly important role in environmental protection [4]. Promoting sustainable entrepreneurship among ambitious entrepreneurs could provide a sound solution to reduce the ecological footprint and help achieve the sustainable development goals [5]. However, entrepreneurship activities are conditioned by intention, people usually do not become entrepreneurs without some trigger and most importantly, intention. Krueger [6] defines entrepreneurial intention as "the commitment that an individual has to starting a new business and it can be considered a key antecedent of entrepreneurial behaviour." Hence, intention is the main factor that shapes one's intention to start a new business, and plays a significant role in the decision to start a new company [7]. The green entrepreneurship intention may be affected by several factors, such as perceived desirability, perceived feasibility, opportunity seeking, and reasonability [8]. Yi [4] argues that green entrepreneurial intentions have a direct positive effect on green entrepreneurship behaviour of university graduates in China.

In Algeria, the authorities are aware of the fundamental role that start-ups play in creating job opportunities and enhancing the growth. As a result, Algerian Start-up Challenge programme (ASC) was started in 2018. In 2020, the Algerian government established a ministry for start-ups, namely "Ministry of Micro-Enterprise, Start-ups and Economy of Knowledge" (MMESEK), whose aim was to remove any obstacles that may hinder start-up creation and functioning. ASC is the biggest Algerian program that generates opportunities for start-up owners and ecosystem actors to create innovation of tomorrow. The first edition focused on enhancing the emergence of start-ups in e-commerce and e-payment in Algeria; the 2nd edition (2020) organized in the form of a national competition aimed to bring together enthusiasts and actors of change in the world of entrepreneurship in Algeria; and the 3rd edition (2021) was organized in the form of specialized challenges by industry and focused on open innovation. In legislative terms, Executive Decree No. 20-254 was issued on September 15, 2020in the official Gazette. The decree governed the establishment of the National Committee that awards the mark of a "start-up enterprise", innovative project, and enterprise incubator. The main goals of this committee are to identify and encourage innovative projects as well as improving their ecosystem. Moreover, in

\footnotetext{
* Corresponding author: shemseddine26000@ gmail.com
} 
its efforts to support start-ups, the Algerian government has granted many tax incentives, including complete exemptions (and sometimes significant reduction) from some taxes and fees (such as the income tax, real estate tax, value-added tax, and professional activity fee), and customs rights of 5 to 10 years.

The decision to become a green entrepreneur may be regarded as voluntary and conscious. Therefore, it is highly recommendable to analyse how such a decision is made [9]. There is an increasingly huge volume of literature arguing that intentions play a fundamental role in the decision to start a new firm [7,9]. In the light of pressure from environmental degradation, entrepreneurs might be compelled to take into account environmental protection measures when they plan to start up an enterprise [10]. Going green has generated a huge enthusiasm in the society; however, green entrepreneurial intention is still evolving [8]. It is worth noting that much of the literature on green entrepreneurship lacks empirical research [11].

Since Ajzen developed the theory of planned behaviour (TPB) in 1991 [12], it has gained a major interest and has been enormously applied worldwide. Results confirm the applicability of the TPB to entrepreneurship, despite some contradictions of various studies [9]. Green entrepreneurship is an intentional and planned behaviour, a complex process consisting of several stages, where in the early stage, when a person becomes a green entrepreneur, a person develops a certain level of green entrepreneurial intention [4]. Sher et al. [5] and Waris et al. [13] applied the extended TPB to identify the drivers of sustainable start-up intentions among students in Pakistan. Kautonen et al. [14] confirmed the relevance and robustness of the TPB in the prediction of business start-up intentions and the following behaviour based on longitudinal survey data (2011 and 2012) from the adult population in Austria and Finland. In addition, some other studies use other theories to investigate green entrepreneurial intention. For example, Ramayah et al. [8] combined the entrepreneurial event theory (EET) and cultural values theory (CVT) as the theoretical framework to determine factors influencing the green entrepreneurial intention in Malaysia. However, in Algeria, no research has been carried out to understand the students' intentions to create green start-ups, which makes this study particularly important and valuable.

Therefore, this paper aims to answer the following research question: What is the influence of TPB constructs, and environmental awareness on intentions to create green start-ups? In this context, the objectives of this paper were to: (1) determine the factors that influence students' intentions to create green start-ups; and (2) develop and validate extended model that combines TPB with environmental awareness. Hence, a survey data from 248 students was used to test our extended model. The following part of this paper is structured as follows: The next section presents the theoretical framework, as well as the formulated hypotheses. The third section describes the methodology, including a sample definition and the measures of constructs. The fourth section presents the finding and discussion, which is followed by conclusion.

\section{Literary research}

\subsection{Attitudes towards green start-ups}

Attitude refers to "the degree to which a person has a favourable or unfavourable evaluation or appraisal of the behaviour in question" (p. 188) [12]. Attitude is the underlying variable of the direct and the indirect effects' confluence that stimulate the intention to behave or not to behave in a specific manner. In the context of entrepreneurship, the attitude towards start-ups was defined as "the degree to which the individual holds a positive or negative personal evaluation about being an entrepreneur" (p.570) [15]. The personal valuation reflects the individual's predisposition to own a business, which may help to form an entrepreneurial intention later; it could be converted to creating a start-up. Interestingly, it was found that U.S. and Turkish students show a low degree of entrepreneurial intentions, even though their attitude towards entrepreneurship is considered positive [7]. A study conducted by Saleem et al. [16] shows that attitude toward eco-entrepreneurship intention remains insignificant, which becomes strong and positive in the presence of two specific moderators, namely altruism and collectivist behaviour. In contrast to earlier findings, a positive attitude was found to be elicited by students' intention to create a start-up [17-19]. Likewise, Vamvaka et al. [20] who found that positive attitude and perceived self-efficacy are certainly the strongest predictors of entrepreneurial intention. Moreover, Peng et al. [10] found that attitude serves as a positive mediator between environmental values and sustainable entrepreneurial intention. Therefore, the following hypothesis is formulated:

H1: Attitudes positively influence intentions to create green start-ups.

\subsection{Subjective norms}

According to Bouarar and Mouloudj [21], subjective norm refers to "the level of social pressures exerted by a reference group that can influence a person's perception, feeling, preference, judgments, attitude, intention, and behaviour" (p.652). In the context of entrepreneurship, social norms represent entrepreneurs' perception of social pressure and significant references about certain entrepreneurial behaviour. Several studies confirm the existence of significant relationships between the intention to start a new business and the fact of knowing a person who owns a business, such as a parent and family members $[17,22]$ or a role model. Previous research shows that subjective norm has a significant impact on entrepreneurial intention [23,24]. Peng et al. [10] found that subjective norm, as a mediator, has a positive impact on the 
link between environmental values and sustainable entrepreneurial intention. Therefore, the second hypothesis is formulated as follows:

H2: Subjective norms positively influence intentions to create green start-ups.

\subsection{Perceived Behavioural Control (PBC)}

PBC was introduced by Azjen [12] as a proximal antecedent of intention, extending the theory of reasoned action (TRA). PBC refers to "the person's perception of the ease or difficulty of performing the behaviour of interest" (p.183) [12]. PBC is related not only to the individuals' perception of their abilities to complete or execute an action, but also their perception to control it [9]. In the context of entrepreneurship, PBC reflects the entrepreneur's confidence in being capable to perform and control entrepreneurial activities. PBC was determined to have a significant impact on the entrepreneurial intention among undergraduate students [22]. Similarly, Yurtkoru [25] believes that PBC has a positive effect on Turkish university students' entrepreneurial intentions, although a slight one. Ashraf [23] clais that PBC has a positive influence on e-commerce bounded entrepreneurial intention. Therefore, the third hypothesis is formulated as follows:

H3: PBC positively influences the intentions to create green start-ups.

\subsection{Environmental Awareness}

Environmental problems are considered global challenges such as global warming, air pollution, and ozone layer depletion. Mouloudj and Bouarar [26] define environmental awareness as "the first level of environmental knowledge the individual owns about the causes and the effects of environmental damage" (p.875). According to entrepreneurial human capital (EHC) theory, individuals who acquire entrepreneurial knowledge presumably become entrepreneurs [27]. Li et al. [28] believe that education in green entrepreneurship promotes and boosts students' perception and behaviour towards green development. An intention to become a green entrepreneur is related to the commitment to buy and offer green products by using environmentally-friendly technology and materials to protect the environment against degradation and restrain or even reduce the depletion of natural resources. According to Peng et al. [10], environmental values have a significant and positive effect on sustainable entrepreneurial intention. It can be argued that environmental awareness is a key requirement to encourage environmentally-friendly behaviour; awareness is thus considered necessary along with other conditions for green entrepreneurship behaviour. The fourth hypothesis is thus formulated as follows:

H4: Environmental awareness positively influences the intentions to create green start-ups.

The summary of the hypotheses formulated within the constructs is shown in Fig.1.

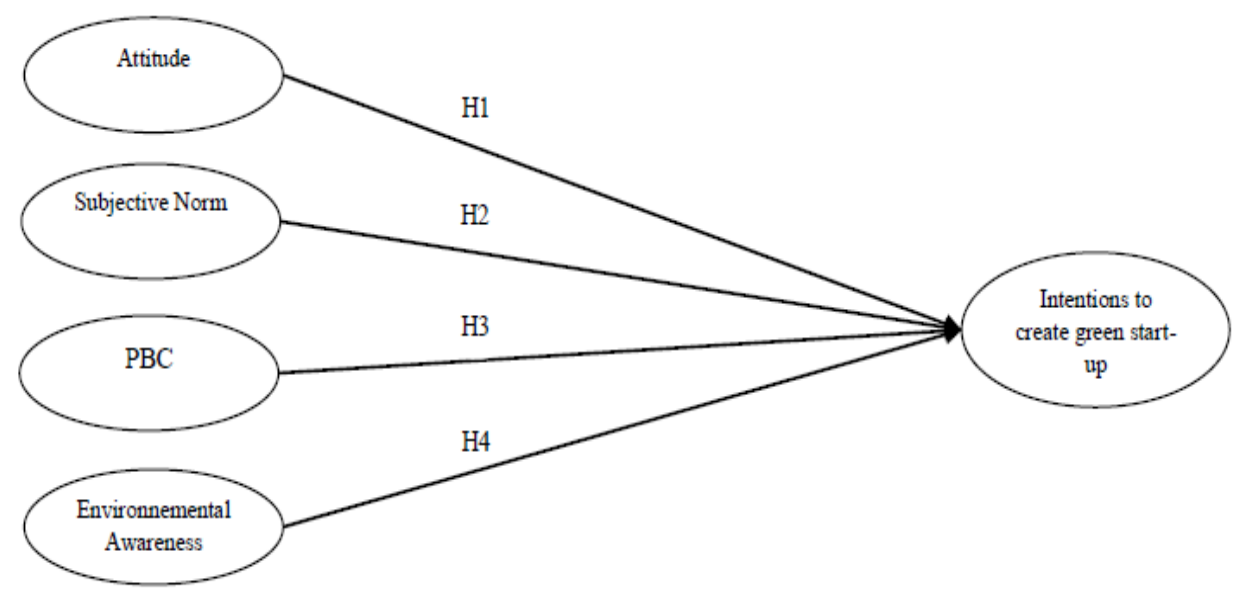

Figure 1. The research framework

Source: Authors.

\section{Methodology}

\subsection{Sample and procedure}

A structured questionnaire was designed for collecting data from a convenience sample. The population for the submitted study includes students of four Algerian universities (University of Algiers, University of Blida, University Setif, and University of Bouira). The selected students specialize in electronics, engineering, agriculture, biology, economic, and business. They were selected for the research because compared to other categories, the student category 
is more likely to be more knowledgeable and aware of the environmental hazards [26]. Moreover, researchers argue it was after graduation stage of development that most of entrepreneurs develop their intentions and engage in start-up activities [4,29]. Participation in the study was voluntary and completely anonymous. In total, 340 questionnaires were distributed, and 251 questionnaires were filled in. However, the analyses were performed on 248 questionnaires because 3 questionnaires were either incompletely or incorrectly filled in. The survey was conducted between 10 April 2021 and 20 June 2021. A total of 248 students were included in the study, with a response rate of 72.29\%. Respondents' demographic analysis characteristics revealed that the sample included $155(62.50 \%)$ men. The mean age among the students was 22.3 years, with the minimum age being 18 years and the maximum age 37 years. With regards to the education level of the students, the majority of participants are Bachelor students $(51.21 \%), 36.69 \%$ participants are Master students, and $12.10 \%$ are doctoral students.

\subsection{Measurement}

The selected data collection method for this research is a questionnaire survey. The questionnaire used reliable and validated scales based on the aforementioned studies. The questionnaire used in this paper included three demographic questions (gender, age, and level of education) along with 16 items about five constructs (see Table 1). Three items adapted to those used by [9] are used to measure attitudes towards green start-ups. Three items developed by [21] are used to measure subjective norms. Three items developed by [9] are used to measure PBC. As for environmental awareness, four items adapted to those used by [26] are used. Finally, three items from [9] were used for measuring the intentions. A five-point Likert scale ranging from (1) strongly agree to (5) strongly disagree. The questionnaire was tested first and then modified to increase its reliability. The questionnaire was originally developed in English, and then translated into Arabic. The two versions of the questionnaire were distributed according to the students' wishes.

Table 1. Measurement of Constructs

\begin{tabular}{lll}
\hline Constructs & Measurement Item & Reference \\
\hline
\end{tabular}

ATT1 Being a green entrepreneur implies more advantages than disadvantages to me.

Attitude

Subjective Norm

Perceived

Behavioural Control (PBC)

Environmental Awareness
ATT2 A career of a green entrepreneur is attractive for me.

ATT3 If I had the opportunity and resources, I'd like to start a green firm.

SN1 If I decided to create a green start-up, most people who are important to me will approve of that decision.

SN2 My family expects me to create a green start-up.

SN3 My colleagues expect me to create a green start-up.

PBC1 To create a green start-up and keep it working would be easy for me.

PBC2 I can control the creation process of a green start-up.

PBC3 If I tried to create a green start-up, I would be likely to succeed.

EA1 By creating a green start-up, I can influence environmental protection.

EA2 I think I have the responsibility to protect the environment.

EA3 I think environmental problems will affect human life.

EA4 I think the environment is getting worse.

IN1 I had a preliminary idea for a green start-up to implement in the future.

IN2 I'm willing to do anything to create a green start-up.

IN3 I'd like to start a green enterprise that would help solve environmental issues. 


\section{Results}

Cronbach's alpha was employed to measure reliabilities among items of TPB constructs, environmental awareness, and intention (Table 2). The minimum coefficient was 0.774 ; a value that exceeds 0.6 means satisfactory internal consistency reliability $[21,26]$. Test of normality is an important postulate of regression analysis. The reliability of the regression result requires the normal distribution of the data. According to Byrne [30], the observed distribution is normal if both the skewness and kurtosis values are close to zero, with a measure of skewness statistics fluctuating around \pm 2 and kurtosis around \pm 7 . The results show that skewness ranges between 0.276 and 1.02 , whereas kurtosis between -0.276 and +1.264 , thus ensuring that the data used in the study is normally distributed.

Table 2. Reliability, multicollinearity, and collinearity test

\begin{tabular}{lccccc}
\hline Constructs & Cronbach's Alphas & Skewness & Kurtosis & Tolerance & VIF \\
\hline ATT & 0.774 & 1,025 & 1,264 &, 451 & 2,220 \\
SN & 0.944 &, 571 &, 302 &, 581 & 1,720 \\
PBC & 0.826 &, 500 &,- 179 &, 389 & 2,573 \\
EA & 0.808 &, 739 &, 495 &, 411 & 2,431 \\
IN & 0.882 &, 276 &,- 267 & - & - \\
\hline
\end{tabular}

Source: Authors.

The presence of multicollinearity through tolerance and variance inflation factor (VIF) were assessed. When tolerance is lower than 0.20 and the VIF value is greater than five, there is an issue of multicollinearity. The results in Table 2 shows that the tolerance value is not lower than 0.2 and VIF does not exceed 5 , which means that multicollinearity is not an issue in this analysis.

To test our research hypotheses, a multiple linear regression was employed. The hypotheses testing results are summarized and presented in Table 3.

Table 3. Multiple regression results for intention to create green start-ups

\begin{tabular}{lcccc}
\hline Model & $\mathrm{B}$ & $\mathrm{t}$ & $\mathrm{S}$ & Decision \\
\hline (constant) & .995 & 6.649 & .000 & - \\
ATT & .246 & 3.487 & .001 & H1 confirmed \\
SN & .161 & 2.628 & .009 & H2 confirmed \\
PBC & .215 & 2.836 & .005 & H3 confirmed \\
EA & .205 & 2.906 & .004 & H4 confirmed \\
\hline
\end{tabular}

Dependent Variable: Intention to create green start-up. Independent variables: Attitude (ATT), Subjective norm (SN), Perceived behavioural control (PBC), Environmental awareness (EA).

Notes: Model summary: $\mathrm{R}=69.2 \%$; R Square $=47.9 \%$; Adjusted R Square $=46.9 \% ; \mathrm{F}=55.820 ; P=0.000(\mathrm{p}<0.05)$.

Source: Authors.

As shown in the table, attitudes have direct and positive influence on the intentions to create green start-ups $(t=3.487$, $\beta=0.246, p=0.001), \mathrm{H} 1$ is thus confirmed. However, subjective norms influence on the intentions to create green startups was found to be statistically significant $(t=2.628, \beta=0.161, p=0.009)$, in this case, H2 was confirmed. The findings indicate that PBC has a direct and positive influence on the intentions to create green start-ups $(t=2.836, \beta=0.215$, $p=0.005)$, and environmental awareness $(t=2.906, \beta=0.205, p=0.004)$, Therefore, H3 and H4 are confirmed. The adjusted $\mathrm{R}$ square indicates the explanatory power of the predictor variable(s) on the respective construct. The attitude, subjective norm, PBC, and environmental awareness, explains about $47 \%$ of intentions to create green start-ups $\left(R^{2}=\right.$ 0.479). 


\section{Discussion}

Our study indicates that attitude towards green start-ups is an important factor of influencing students' intentions to create green start-ups, which supports previous findings by [17-20]. This means that people form positive intention to engage in a creating green start-ups when their attitudes are positive; this also means that the stronger the attitudes are, the more likely it is to create green start-ups. However, intention may not lead to behaviour for several reasons, especially when fundraising is an issue. Undoubtedly, thousands of projects (green or not green) were not implemented due to lack of financial resources or administrative obstacles.

In the same vein, it was found that subjective norms have a strong positive influence on the intentions to create green start-ups. This suggests that for subjective norms, the perceptions of other important individuals (such as families, teachers, relatives, or peers) have a strong direct effect on the intention of creating green start-ups. This indicates that subjective norm reflects the perceived social pressure for conducting a particular behaviour, it is a factor of an individual's beliefs, represents social pressure put on entrepreneurs and is considered prior to any behaviour. Therefore, entrepreneurs may be influenced by information from environmental awareness groups who make claims about the positive effects of green entrepreneurship. Our finding is consistent with several studies indicating that subjective norms have a significant positive effect on sustainable entrepreneurial intentions [10,23,24].

Moreover, results show that PBC has a significant and positive influence on the intentions to create green start-ups. In this context, $\mathrm{PBC}$ reveals perception regarding access to resources and opportunities needed to carry out the behaviour, including access to financial resources, time, and other resources, and the person's self-confidence in the capacity to conduct the green entrepreneurship behaviour. This suggests that the high level of PBC should increase university students' intention to create green start-ups. In this sense, this finding was consistent with [22] and [25], according to whom the PBC positively influence students' entrepreneurial intentions. It is also supported by Ashraf [23], who found that PBC positively influence Facebook commerce entrepreneurial intention. In practice, it is expected that potential Algerian green entrepreneurs in the Algerian environment will encounter several obstacles, first financial obstacles that stem from the difficulty of convincing investors or sponsors of the feasibility of green projects, second, the institutional context in which they operate due to the monopoly power of incumbents in the energy industry, which hinders the provision of alternative energy sources. Thirdly, technological obstacles (lack of knowledge of green technology), administrative obstacles (lack of transparency when applying for government support). There might be other barriers such as legislation and law regulating the industry in which they operate.

Finally, the results indicate that environmental awareness has a strong direct influence on the intentions to create green start-ups. This means that students with high level of environment awareness and having good knowledge regarding the environment issues are more likely to engage in creating green project after graduation, in other words, students' intention is highly influenced by their environmental awareness level. Contrary to what was expected it has been found that students' environmental awareness is very low (mean=2.48), which means that they are not exposed to environmental issues and topics in their studies at university; in this regard, it is necessary to increase their awareness of this issue. Environment awareness may switch negative attitudes to positive ones tremendously, and can also influence the sense of environmental responsibility, which, in turn, may enhance people to create green projects.

\section{Conclusion}

Yi [4] considers green entrepreneurship as the solution to the environmental and social issues. In addition, research confirms that intentions play a significant role in the decision to start a new business [7]. This paper is aimed at developing and examining extended TPB model that evaluates how attitude, subjective norm, PBC, and environmental awareness influence the students' intentions to create green start-ups. To the best of our knowledge, the presented study is the first attempt to investigate this topic in Algeria. For the purposes of this paper, a questionnaire was distributed to a convenience sample of 340 students from six Algerian universities, and 248 properly filled in questionnaires were obtained. The findings show that most students were found to have low environmental awareness (Mean=2.48). The findings also indicate that the three constructs of the TPB along with environmental awareness have a significant positive influence on the intentions to create green start-ups, and the four factors combined explain $47.9 \%$ of the variance in behavioural intention. All the hypotheses were confirmed; the findings from this paper thus contributes to the growing volume of research literature on green entrepreneurship intentions.

\subsection{Managerial implications}

The results indicate that attitude is the most significant factor of students' intention to create a green start-up; therefore, positive attitudes should be strengthened towards green entrepreneurship. In this vein, providing high quality information regarding the personal benefits of creating green projects is the main antecedents of a positive attitude, potential entrepreneur's beliefs regarding the profits that a green project could generate can significantly stimulate the intention to create a green enterprise in the future through promoting previous successful green project such as sharing videos of a successful green entrepreneurs on social media or airing videos on reliable and renowned TV channels (either local or international). The importance of launching green projects for increasing opportunities to enter international markets can 
also be highlighted. The results also indicate that social norms play a key role in shaping the intention to create green start-ups, which means that parents (as a reference group) should actively guide and enhance ambitious youth to create green products; opinion leaders such as university teachers, religious scholar) may effectively contribute as well. Furthermore, the results indicate that the intention to create a green start-up is highly influenced by the PBC; therefore, any obstacles that hinder the idea of creating a green start-up should be removed, mainly in the situation when green startup projects in Algeria are still in the infancy stage and unclear. The obstacles that may hinder the idea of creating a green start-up to come into being include lack of knowledge regarding legal procedures, bureaucracy and complex administrative procedures, lack of knowledge regarding green financing sources, ambiguity on how to market green products, and lack of knowledge about green technology. Therefore, MMESEK ought to identify these obstacles and cooperate with the other ministries to find practical and useful solution. Finally, the results indicate that environmental awareness directly affects the intention to create green firms; therefore, different stakeholders (especially the MMESEK) need to encourage students to create start-ups as well as to increase their environmental awareness through TV conferences, organizing international conferences, and distributing leaflets. Universities can also play a pivotal role in increasing student environmental awareness through incorporating environmental issues in the educational curriculum and programs (such as green economy, green marketing, environment accounting, green entrepreneurship, etc.). Organizing national competition and awarding valuable awards for the best green innovative project can also be very fruitful to encourage young entrepreneurs to channel their innovative efforts and ideas towards innovative green projects.

\subsection{Limitations and future research directions}

This research is not without limitations. First, the sample size in this study is relatively small ( 248 students). Therefore, further studies should include a larger sample. Second, our study used convenient sampling, which limits the ability to generalize the results of the study. It is thus recommended to use random sampling to generalize results. Third, this study addressed students' intentions to create green start-ups; therefore, futher research into the current green entrepreneurs' behaviour is recommended to properly explore the transition from intentions into behaviour. Fourth, the current study incorporated environment awareness in the TPB; further research may include other variables such as entrepreneurial knowledge, perceived entrepreneurial risk-taking, individual traits, religious values, and any other variables that can enhance the explanatory robustness of the extended model.

\section{References}

1. R. Nordin, N.A. Hassan. The role of opportunities for green entrepreneurship towards investigating the practice of green entrepreneurship among SMEs in Malaysia. Review of Integrative Business and Economics Research. 8, 99116 (2019)

2. M. Vuola, M. Korkeakoski, N. Vähäkari, M.B. Dwyer, N.J. Hogarth, J. Kaivo-oja, J. Luukkanen, E. Chea, T. Thuon, K. Phonhalath. What is a green economy? Review of national-level green economy policies in Cambodia and Lao PDR. Sustainability. 12(16), 6664 (2020)

3. D.A. Shepherd, H. Patzelt. The new field of sustainable entrepreneurship: Studying entrepreneurial action linking "what is to be sustained" with "what is to be developed". Entrepreneurship: Theory and Practice. 35(1), 137-163 (2011)

4. G. Yi. From green entrepreneurial intentions to green entrepreneurial behaviors: The role of university entrepreneurial support and external institutional support. International Entrepreneurship and Management Journal. 17, 963-979 (2020)

5. A. Sher, A. Abbas, S. Mazhar, G. Lin, Fostering sustainable ventures: Drivers of sustainable start-up intentions among aspiring university students in Pakistan. Journal of Cleaner Production. 262, 121269 (2020)

6. N. F. Krueger. The impact of prior entrepreneurial exposure on perceptions of new venture feasibility and desirability. Entrepreneurship Theory and Practice. 18(1), 5-21 (1993)

7. N. Ozaralli, N.K. Rivenburgh. Entrepreneurial intention: antecedents to entrepreneurial behavior in the U.S.A. and Turkey. Journal of Global Entrepreneurship Research. 6(3), 1-32 (2016)

8. T. Ramayah, S. A. Rahman, S. K. Taghizadeh. Modelling green entrepreneurial intention among university students using the entrepreneurial event and cultural values theory. International Journal of Entrepreneurial Venturing. 11(4), 394-412 (2019)

9. F. Liñán, Y. Chen. Development of cross-cultural application of a specific instrument to measure entrepreneurial intentions. Entrepreneurship Theory and Practice. 33(3), 593-617 (2009)

10. H. Peng, B. Li, C., Zhou, B. M. Sadowski. How does the appeal of environmental values influence sustainable entrepreneurial intention? International journal of environmental research and public health. 18(3), 1070 (2021) 
11. J. Amankwah, H. Sesen. On the relation between green entrepreneurship intention and behavior. Sustainability. 13(13), 7474 (2021)

12. I. Ajzen. The theory of planned behavior. Organizational Behavior and Human Decision Processes. 50(2), 179-211 (1991)

13. I. Waris, M. Farooq, I. Hameed, A. Shahab. Promoting sustainable ventures among university students in Pakistan: an empirical study based on the theory of planned behavior. On the Horizon. 29(1), 1-16 (2021)

14. T. Kautonen, M. van Gelderen, M. Fink, Robustness of the theory of planned behavior in predicting entrepreneurial intentions and actions. Entrepreneurship Theory and Practice. 39(3), 655-674 (2015)

15. V. Souitaris, S. Zerbinati, A. Al-Laham. Do entrepreneurship programmes raise entrepreneurial intention of science and engineering students? The effect of learning, inspiration and resources. Journal of Business Venturing. 22(4), 566-591 (2007)

16. F. Saleem, A. Adeel, R. Ali, S. Hyder. Intentions to adopt ecopreneurship: Moderating role of collectivism and altruism. Entrepreneurship and Sustainability Issues. 6(2), 517-537 (2018)

17. K. Soria-Barreto, G. Honores-Marin, P. Gutiérrez-Zepeda, J. Gutiérrez-Rodríguez. Prior exposure and educational environment towards entrepreneurial intention. Journal of Technology Management \& Innovation. 12(2), 45-58 (2017)

18. B. Usman, Y. Yennita. Understanding the entrepreneurial intention among international students in Turkey. Journal of Global Entrepreneurship Research. 9, 1-21 (2019)

19. W. Widayat, N. Ni'matuzahroh. Entrepreneurial attitude and students business start-up intention: A partial least square modeling. Jurnal Manajemen dan Kewirausahaan. 19(1), 46-53 (2017)

20. V. Vamvaka, C. Stoforos, T. Palaskas, C. Botsaris. Attitude toward entrepreneurship, perceived behavioral control, and entrepreneurial intention: dimensionality, structural relationships, and gender differences. Journal of Innovation and Entrepreneurship. 9, 1-26 (2020)

21. A.C. Bouarar, K. Mouloudj. Using the theory of planned behavior to explore employee's intentions to implement green practices. Dirassat Journal Economic Issue. 12(1), 641-659 (2021)

22. S. N. A. Ambad, D. H. D. A. Damit. Determinants of entrepreneurial intention among undergraduate students in Malaysia. Procedia Economics and Finance. 37, 108-114 (2016)

23. M. A. Ashraf, M. M. D. Alam, L. Alexa. Making decision with an alternative mind-set: Predicting entrepreneurial intention toward f-commerce in a cross-country context. Journal of Retailing and Consumer Services. 60, 102475 (2021)

24. S. Sabah. Entrepreneurial Intention: Theory of planned behaviour and the moderation effect of start-up experience. In: M. Franco. Entrepreneurship: Practice-Oriented Perspectives. 87-101. Turkey: Ankara University (2016)

25. E. S. Yurtkoru, Z. K. Kuşcu, A. Doğanay. Exploring the antecedents of entrepreneurial intention on Turkish university students. Procedia - Social and Behavioral Sciences. 150, 841-850 (2014)

26. K. Mouloudj, A.C. Bouarar. The impact of word of mouth on intention to purchase green products: An empirical study. Revue Algérienne d'Economie et Gestion. 15(1) 871-890 (2021)

27. H. Ni, Y. Ye. Entrepreneurship education matters: Exploring secondary vocational school students' entrepreneurial intention in China. Asia-Pacific Education Researcher. 27(5), 409-418 (2018)

28. H. Li, J. Chen, X. Xu, Z. Zhao. Research on the trend of green entrepreneurship education in colleges and universities. China Market. 52, 71-74 (2016)

29. B. Fuller, L. Yan, S. Bajaba, L. E. Marler, J. Pratt. Examining how the personality, self-efficacy, and anticipatory cognitions of potential entrepreneurs shape their entrepreneurial intentions. Personality \& Individual Differences. 125, 120-125 (2018)

30. B.M. Byrne. Structural Equation Modeling with AMOS: Basic Concepts Applications, and Programming. London: Routledge (2016) 